\title{
Understanding and Addressing Problems in Research Collaboration: A Qualitative Interview Study From a Self-Governance Perspective
}

\author{
Florian Meißner ${ }^{1}$, Carina Weinmann ${ }^{2 \star}$ and Gerhard Vowe ${ }^{3}$ \\ ${ }^{1}$ Department of Culture, Media, Psychology, Macromedia University of Applied Sciences, Cologne, Germany, ${ }^{2}$ Department \\ of Social Sciences, Heinrich Heine University of Düsseldorf, Düsseldorf, Germany, ${ }^{3}$ Center for Advanced Internet Studies \\ (CAIS), Bochum, Germany
}

OPEN ACCESS

Edited by:

Jennifer Dusdal,

University of

Luxembourg, Luxembourg

Reviewed by:

Xue Gao,

University of Miami, United States

Kenneth Evans,

Rice University, United States

*Correspondence:

Carina Weinmann

c.weinmann@hhu.de

Specialty section:

This article was submitted to

Research Policy and Strategic

Management

a section of the journal

Frontiers in Research Metrics and

Analytics

Received: 16 September 2021 Accepted: 14 December 2021

Published: 03 February 2022

Citation:

Meißner F, Weinmann $C$ and Vowe $G$ (2022) Understanding and Addressing

Problems in Research Collaboration:

A Qualitative Interview Study From a

Self-Governance Perspective.

Front. Res. Metr. Anal. 6:778176.

doi: 10.3389/frma.2021.778176
For collaborative research to be successful, understanding and solving collaboration problems is of paramount importance. However, theory-driven research on this issue at a general level is scarce. Drawing from two micro-oriented approaches (i.e., club theory and commons theory) and relying on self-governance as the basic principle for addressing collaboration problems, we aim to develop theoretically informed, concise and generalizable catalogs of problems and solutions based on the experiences and expectations of research collaboration participants. A series of expert interviews $(N=18)$ were conducted with leading researchers in Germany. Seven typical problems (e.g., lack of commitment or fairness) and 12 possible solutions (e.g., continuous evaluation or creating cognitive common ground) that can be applied within the self-regulatory framework were identified. The results provide a useful framework to further investigate problems and solutions as well as interlinkages between the two, and to improve research collaboration.

Keywords: research collaboration, collaborative research, collaboration problems, solutions, self-governance, club theory, commons theory, expert interviews

\section{INTRODUCTION}

The growing importance of collaborative research in science can be observed, for example, in the increasing number of co-authored publications (Gross et al., 2017; Hackett et al., 2017). As research collaborations (RCs) are one of the most efficient ways to tackle complex research issues, they have become the most common form of scientific work (see e.g., Katz and Martin, 1997; Beaver, 2013; Bozeman and Youtie, 2017; Wagner, 2019). However, like any other type of collaboration, RCs face specific problems, including personal differences between participants or ineffective communication (e.g., Youtie and Bozeman, 2014; Bozeman et al., 2016). If such problems are not addressed, substantial risks to productivity and to the success of scientific work may result (e.g., Bozeman et al., 2016; Sacco, 2020). While there are studies which provide comprehensive lists of factors that are either detrimental or supportive in the context of RC for specific disciplines (e.g., Bozeman et al., 2016; Volk, 2021), this issue has not been addressed for RC in general. Furthermore, we do not see an integrative theoretical basis from which potential problems and appropriate solutions might be derived. In our view, such a basis is crucial: While pragmatic reactions to problems seem to be popular and might be useful on an everyday basis, they do not allow for the generalization of researchers' experiences with collaboration problems and of solutions which 
can be relied upon beyond single contexts. We therefore aim to address these research gaps by systematizing and generalizing the problems typically faced by researchers in RC, and by gleaning researchers' suggestions to address and solve these problems.

The present study is based on the assumption that problems arise from inside a RC and that these problems need to be addressed by those who are involved. As such, we focus not on external problems such as changes to national science policy, but rather on internal problems. In our understanding, a collaboration problem arises if a substantial proportion of participants perceive that the current collaboration practice deviates from their expectations of how collaboration should look. Our focus lies on normative expectations: In contrast to empirical expectations, which describe what individuals expect others to actually do, normative expectations refer to how individuals think others should behave (see Bicchieri, 2006). For instance, a researcher may perceive that his/her collaborators are not behaving as ethically as expected (e.g., Sacco, 2020). Accordingly, our first research question is as follows:

RQ1: Which problems do researchers perceive with regard to RC?

Scholars often refer to external forces such as science policy makers, state funding agencies, or bureaucratic mechanisms in order to conceptualize the governance of science (e.g., Shrum et al., 2007; Bora, 2012; Hackett et al., 2017; Gläser, 2019). However, we assume that collaboration problems must be solved within the very context of RC, which is why we focus on internal governing mechanisms. We thus suggest self-governance as the basic principle for solving collaboration problems. Moreover, we understand that solutions to collaboration problems encompass approaches that participants consider to be useful for converging the current practice of collaboration toward their expectations. In this sense, solutions can be seen as the means with which to address or even prevent collaboration problems. Therefore, our second research question is:

RQ2: Which problem solutions do researchers within RC perceive as useful?

The answers to these research questions should be of theoretical relevance by contributing to a more thorough understanding of RC: We aim to develop theoretically informed and empirically based catalogs of collaboration problems and possible solutions, which are based on the experiences and expectations of researchers and may be used as a basis for further empirical research. Concerning the practical relevance, the answers should enhance the productivity and efficiency of collaborative research: The greatest possible benefits (e.g., gain of scientific knowledge, technological innovations) with the lowest possible consumption of resources might be achieved. We begin with a review of the current state of research, which shows a rather fragmented picture of problems and solutions as well as a rather thin theoretical basis. Subsequently, we provide an integrative micro-theoretical basis upon which to understand collaboration problems and identify problem solutions. After explaining the method and sample of our qualitative interview study, we generate differentiated catalogs of collaboration problems and solutions to these problems. Lastly, we outline how our findings contribute to painting a clearer picture of the fragmented research on problems and problem solutions in RC, and how they can be used by leading researchers and research managers.

\section{STATE OF RESEARCH: PROBLEMS AND SOLUTIONS IN THE CONTEXT OF RESEARCH COLLABORATION}

We understand research collaborations (RCs) as inter- or intraorganizational teams of researchers who work together in order to achieve a common research objective, while their research project is limited in time and mostly funded by external resources (see e.g., Katz and Martin, 1997; Bozeman et al., 2013; Kosmützky, 2018). In contrast to larger collaborations, such as those examined in the prominent study by Shrum et al. (2007), the associations we address only exhibit a low level of bureaucracy. They consist of a smaller or greater number of participants, who form a community comprising all individuals who are scientifically involved in a collaboration, i.e., the leadership (speakers and coordinators), principal investigators, as well as further participants (postdocs and doctoral students). Beyond science and technology studies as the primary domain, RC has been studied by a variety of other disciplines, including the economic sciences (e.g., Ankrah and AL-Tabbaa, 2015; Baurmann and Brennan, 2016), sociology (e.g., Lewis et al., 2012; Costa, 2014), psychology (e.g., Cummings and Kiesler, 2007; Akkerman et al., 2012), or communication science (e.g., Wöhlert, 2020; Volk, 2021). A wide range of questions and actor constellations have been investigated, from universityindustry collaborations (e.g., Mascarenhas et al., 2018; Vick and Robertson, 2018), through collaborations between universities or research centers (e.g., Adams et al., 2005; Muriithi et al., 2018), to $\mathrm{RC}$ that also includes further actors like public governance institutions (e.g., Kezar, 2005; Yang, 2018).

\section{Insights Into Collaboration Problems}

Previous research has identified diverse problems that occur in collaborative research. Most of all, studies mention various forms of differences that can lead to collaboration problems, for example:

- disciplinary differences (e.g., Cummings and Kiesler, 2008),

- different institutional logics (e.g., Cummings and Kiesler, 2007; Bjerregaard, 2010; Garcia et al., 2019),

- different perspectives, styles of working, and priorities of participants (e.g., Adler et al., 2009; Bozeman et al., 2016; Garcia et al., 2019),

- different educational contexts (e.g., Goddard et al., 2006; Volk, 2021),

- gender and cultural differences (e.g., Bozeman and Gaughan, 2011; Abramo et al., 2013; Dusdal and Powell, 2021).

Additionally, ineffective or insufficient communication (e.g., Barnes et al., 2002; Cohen et al., 2011; Wöhlert, 2020) and status and role conflicts (e.g., Hackett, 2005; Bendersky and Hays, 2012; Youtie and Bozeman, 2014) are regarded as prominent problems. A lack of experience and commitment of participants (e.g., 
Barnes et al., 2002; Gaskill et al., 2003; Bozeman et al., 2016) and unprofessional or inefficient leadership and management (e.g., Adler et al., 2009; Bozeman et al., 2016; Volk, 2021) are further recurrent problems. Less frequently named examples are a lack of sustainability in funding (Goddard et al., 2006; Adler et al., 2009; Volk, 2021), the relation between individual costs and benefits (Berlemann and Haucap, 2015), geographical distance (Goddard et al., 2006; Cummings and Kiesler, 2008; Volk, 2021), the size of the research team (e.g., Cummings and Kiesler, 2008; Cummings et al., 2013), a high level of bureaucracy in institutions (e.g., Muriithi et al., 2018), or unforeseeable risks like the premature disclosure of results by participants (e.g., Hoecht, 2004; Hackett et al., 2017; Garcia et al., 2019).

\section{Insights Into Solutions to Collaboration Problems}

Previous research also suggests a variety of individual solutions to collaboration problems. The most frequently mentioned solutions by far include competent leadership and management (e.g., Vonortas and Spivack, 2006; Schützenmeister, 2010; Volk, 2021) and effective and continuous communication, negotiation, and networking (e.g., Jeffrey, 2003; Vicens and Bourne, 2007; Luo and Omollo, 2013). Further prominent examples include fostering commitment, trust, and a good relationship between collaborators (e.g., Chompalov and Shrum, 1999; Shrum et al., 2001, 2007; Bruneel et al., 2010) and the provision of funding, incentives, and rewards as well as motivating participants (e.g., Heller and Michelassi, 2012; Currie-Alder et al., 2018; Wagner et al., 2019).

Furthermore, working with previous collaboration partners (Chapman et al., 2018; Liang and Liu, 2018; Hewitt-Dundas et al., 2019), optimal team size and composition (e.g., Porac et al., 2004; Holl and Rama, 2019; Mirnezami et al., 2020), and working with partners with similar styles of working and objectives (e.g., Hara et al., 2003) are also regarded as effective, albeit less frequently. Some studies also highlight the definition of clear objectives (e.g., Bjerregaard, 2009; Begun et al., 2010; Lee and Mitchell, 2011), project planning and monitoring (e.g., Segalla, 1998; Barnes et al., 2002; Morandi, 2013), as well as an efficient and appropriate division of labor (e.g., Raadgever et al., 2012; Jeong and Choi, 2015; Haeussler and Sauermann, 2020). Individual studies also point, for example, to the use of interdisciplinary working methods (Scanlon et al., 2019), to the recognition and bridging of individual differences such as race or gender (e.g., Ettorre, 2000; Bammer, 2008), or to a strong group identity (e.g., Jackson, 2011).

This review demonstrates the variety of individual approaches to collaboration problems and their solutions. However, the overall picture is rather fragmented: Research has often focused on individual problems and solutions instead of targeting the "whole picture." And those exceptions which provide comprehensive lists of challenges for collaborative research and ways to solve them focused on specific disciplines like the STEM fields (Bozeman et al., 2016) or communication science (Volk, 2021). Moreover, while scholarship on RC is constantly growing, just as the phenomenon itself (e.g., Hackett et al.,
2017; Mascarenhas et al., 2018), the theoretical basis of this line of research is rather thin and extremely diverse. This is problematic insofar as we are left without a thorough theoretical understanding of why and how which kinds of collaboration problems emerge. Furthermore, without a solid theoretical basis, we can hardly determine which solutions might be most effective and who should be held responsible. To summarize, as yet, systematic and generalizable catalogs of problems and solutions that are interlinked and coherently derived from an integrative theoretical basis and applicable to RC in general are lacking. As such catalogs should facilitate the diagnosis of collaboration problems and how they are dealt with, we aim to address this issue and will elucidate our theoretical perspective in the following section.

\section{THEORETICAL BACKGROUND: CLUB THEORY AND COMMONS THEORY}

Our study is based on the assumption that collaborative research, i.e., the processes, rules, and procedures, is mainly driven by the involved researchers themselves. Accordingly, central problems in collaborative research arise from individual perceptions, interactions, and relationships within a research team itself, and therefore have to be solved within this very group of researchers. Thus, in contrast to studies that take a meso perspective (e.g., Shrum et al., 2007), our emphasis on the individuals involved in collaboration calls for a micro-theoretical view. The core of the theoretical framework is thus an approach which combines two decidedly micro-oriented perspectives: club theory (Buchanan, 1965) and commons theory (Ostrom, 1990, 2005). These theories allow us to understand collaboration problems and potential solutions based on the individual perspectives and the tension that exists between individual and common interests. Both theories have proven to be valuable in other contexts. For example, club theory has been used to explain the functioning of voluntary programs (Prakash and Potoski, 2009), while commons theory has been applied to traditional topics like fishery and forestry and to newer ones such as climate change and digital commons issues (van Laerhoven and Ostrom, 2007). Both theories promise conceptual clarity in our context: On the one hand, club theory helps to disentangle the complexity of different goods and processes in RCs and to diagnose resulting problems. Commons theory, on the other hand, is useful to retrace the principle and process through which collaboration problems can be solved.

\section{A Club Theory Perspective on RCs}

Following club theory (Buchanan, 1965; Cornes and Sandler, 1996), a RC may be conceived of as a club, that is, as an interactive context that enables a group of actors, defined by their collaboration membership, to exclusively produce and consume a specific club good. With this theory, Buchanan emphasized the fact that there are further types of goods besides private and public goods (Sandler and Tschirhart, 1997). Club goods represent, in addition to private, public, and common goods, a fourth type of goods that is typically differentiated in economic 
theory (Ostrom et al., 1994). In contrast to private and common goods, they are not shaped by rivalry. This means the use by some does not make these goods less available to others. However, like private goods they are characterized by exclusiveness: Only club members are allowed to use its good. An everyday example is a golf club, with the exclusive club good of using a golf course (Buchanan, 1965). In the case of RCs, the specific club good is the joint production and use of an exclusive research opportunity (Baurmann and Vowe, 2014), which depends upon collaboration. Prototypically, this opportunity manifests itself in a joint application for third-party funding, in the research plan of a multi-disciplinary project group, or in the collaborative usage of research facilities. Of course, there may be other goods resulting from a RC that are non-exclusive, for example, knowledge. However, in our view, the exclusive research opportunity is the core good of a RC.

The club members' collaboration to produce and consume the good results in a series of specific problems, which can be traced back to the nature of a club good: Because it is collaboratively used by the club members, it should be equally available to all of them and at the same time be produced in a cooperative way (Baurmann and Vowe, 2014). Whenever this is not the case, one or several problems may occur. For example, the recurrent collaboration problem of fairness (e.g., Berlemann and Haucap, 2015; Bozeman et al., 2016; Johann et al., 2020) can be well-explained in terms of club theory: In the production and use of the club good, an appropriate reciprocity of input and output by and for everyone must be guaranteed. However, in a research team, there are also incentives for participants to limit their input at the expense of others or to take advantage of others. One important driving factor in this context is the principle of competition for authorship and reputation, which is deeply rooted in science. Therefore, self-interested behavior of individual participants may ultimately harm common interests. Another problem that can be traced back to the nature of a club is the issue of commitment (Baurmann and Vowe, 2014): A club always depends on the (long-term) investment of its members in order to work on a stable basis. This is not different for a RC, which depends on the input and efforts of all researchers involved.

\section{A Commons Theory Perspective on RCs}

Commons theory (Ostrom, 1990, 2005) allows us to understand the principle and process through which collaboration problems can be solved. The crucial insight of this theory may be subsumed under the term self-governance: To best ensure a sustainable use and provision of their goods, communities are assumed to rely on self-regulation and not on other mechanisms like the state or the market (Ostrom, 1990). This includes not only defining suitable rules for the solution of potential collaboration problems but also successfully implementing and enforcing them. According to several case studies, this approach has proven to be superior to other governance mechanisms (Ostrom, 1990, 1999). Selfgovernance allows for an adjustment of the rules to local circumstances and increases the commitment of all community members and the binding character of their agreements.
Hence, through the lens of commons theory, RC is seen as an autonomous community that organizes and self-regulates the sustainable production and use of its good. It represents a useful framework for the study of RC because the principle of selfgovernance is consistent with academic practices and values, for example the self-administration of universities and the belief in freedom of science. Thus, the theory may be used to derive specific approaches for handling the good of a RC.

To summarize, in accordance with club theory, we define RCs as clubs which both produce and consume a specific club good (i.e., an exclusive research opportunity), which helps us to conceptualize potential collaboration problems. Commons theory allows us to understand the mechanisms of selfgovernance in collaboration and therefore to identify solutions for the occurring problems. The key to both understanding and addressing problems in collaborative research are, in our view, the experiences and expectations of RC participants. This concurs with an understanding of collaboration problems that has been outlined by Sacco (2020), who argued that failure of RC may result from unmet expectations of the researchers involved and thus from their individual experiences during collaboration. Therefore, these expectations can explain why collaboration might become problematic. Reconstructing the expectations of researchers involved in collaboration will facilitate our understanding of both problems and solutions.

\section{Summary of the Known (or Assumed) Problems and Solutions}

The problems that we derived from club theory and from the various empirical findings are shown in Table 1.

An overview of the solutions is provided in Table 2 (selection of the most frequently mentioned findings).

\section{DATA AND METHODS}

Our theoretical background helped us to take new perspectives as a starting point for our empirical investigation. As this innovative view calls for an exploratory procedure, we conducted a qualitative interview study. In our study, we followed a deductive-inductive approach with the central objective of testing and iteratively developing a set of analytical categories for problems and solutions in RC. The deductive categories were based on the problems and solutions derived from theory and empirical evidence (see Tables 1, 2). The inductive categories

TABLE 1 | Problems in RCs as derived from theory and empirical findings.

\begin{tabular}{ll}
\hline Problem & Source \\
\hline Fairness & Club theory (Buchanan, 1965) \\
Commitment & $\begin{array}{l}\text { Club theory (Buchanan, 1965) and empirical evidence (e.g., } \\
\text { Bozeman et al., 2016) }\end{array}$ \\
$\begin{array}{l}\text { Difference } \\
\text { Eommunication }\end{array}$ & Empirical evidence (e.g., Bozeman et al., 2016) \\
Management & Empirical evidence (e.g., Vöhlert, 2020)
\end{tabular}


were then developed on the basis of the interviews we conducted, aiming (1) to differentiate and add depth to the known/assumed problems and (2) to identify new problems and solutions. This process continued until the researchers observed that problems and solutions reached the state of theoretical saturation, meaning that as the analysis proceeded, the material yielded no substantial further differentiations or new problems/solutions.

\section{Study Population}

The study included 18 in-depth interviews with 19 academic researchers from seven collaborative research teams in Germany. We selected the teams so as to ensure the coverage of a wide range of disciplines (including interdisciplinary teams) as well as different team sizes and constellations (including both

TABLE 2 | Solutions for problems in RCs as derived from theory and empirical findings.

\begin{tabular}{ll}
\hline Solution & Source \\
\hline $\begin{array}{l}\text { Basic principle of self-governance } \\
\text { Competent leadership and } \\
\text { management }\end{array}$ & Commons theory (Ostrom, 1990) \\
$\begin{array}{l}\text { Effective and continuous } \\
\text { communication, negotiation, and }\end{array}$ & Empirical evidence (e.g., Luo and \\
networking & Omollo, 2013) \\
$\begin{array}{l}\text { Fostering commitment, trust, and a } \\
\text { good relationship between } \\
\text { collaborators }\end{array}$ & Empirical evidence (e.g., Shrum et al., \\
$\begin{array}{l}\text { Provision of funding, incentives, and } \\
\text { rewards as well as motivating }\end{array}$ & 2007) \\
participants & Empirical evidence (e.g., Wagner \\
$\begin{array}{l}\text { Working with previous collaboration } \\
\text { partners }\end{array}$ & et al., 2019) \\
Optimal team size and composition & Empirical evidence (e.g., \\
& Empirical evidence (e.g., Mirnezami \\
Working with partners with similar & et al., 2020) \\
styles of working and objectives & Empirical evidence (e.g., Hara et al., \\
& 2003 )
\end{tabular}

academic-only and university-industry collaboration teams). The key criteria for sampling were the degree of (1) disciplinary and (2) organizational heterogeneity. Based on the number of science areas represented in the RC (Humanities, Social Sciences, Engineering, Natural Sciences, Life Sciences) and the number of organization types (universities, universities of applied sciences, research institutes, large enterprises, $\mathrm{SME}, \mathrm{NGO}, \ldots$ ), we calculated a heterogeneity score. This score ranged from 2 (a small RC involving only university researchers in the same field of science) to 7 (RC including 3 different fields of science and four organization types). Table 3 shows the seven different RCs, the disciplines involved, and their heterogeneity score.

From each team, we interviewed two or three researchers with different roles: speakers $(n=7)$, principal investigators $(n=8)$, and in some cases managing coordinators $(n=4)$. In one case, a speaker and a coordinator were interviewed together; therefore, the total number of informants $(N=19)$ is higher than the number of interviews.

\section{Interview Protocol}

Two authors of this paper conducted the interviews, some jointly and others individually, between April 2019 and May 2020. While in 2019 the interviews were conducted face-to-face $(n=9)$, the COVID-19 pandemic forced us to switch to online interviews in $2020(n=9)$. The interviews were based on a method developed by Gläser and Laudel (2009); see also Laudel and Gläser (2008) and lasted between 70 and $135 \mathrm{~min}$. In total, the recorded interviews had a duration of $27: 39 \mathrm{~h}$. After some opening questions, we asked the respondents to report on the problems we suggested as well as further problems, and on approaches to solve these problems. These questions were derived based on the problems and solutions which we identified through the theoretical foundation of our study and the above-mentioned state of research. The protocol was developed iteratively, integrating new problems and solutions found in previous interviews within our study. In order to achieve a common understanding of the problems and possible solutions, problems were described in detail and examples discussed in the interviews.

TABLE 3 | Key characteristics of the seven RCs under investigation.

\begin{tabular}{|c|c|c|c|}
\hline Research theme & Fields of research & Organization types & $\begin{array}{l}\text { Heterogeneity } \\
\quad \text { index }\end{array}$ \\
\hline Heart valve infections & Life Sciences (1) & Universities (1) & 2 \\
\hline Crop science & Life Sciences (1) & Universities, research institutes (2) & 3 \\
\hline Robots in logistics & Engineering (1) & University, SME, large enterprise (3) & 4 \\
\hline Sustainable traveling & Social Sciences (1) & University, SME, industry association (3) & 4 \\
\hline IT security & $\begin{array}{l}\text { Engineering, Humanities, Social } \\
\text { Sciences (3) }\end{array}$ & University, university of applied sciences (2) & 5 \\
\hline Methane as fuel & Engineering (1) & $\begin{array}{l}\text { Universities, universities of applied sciences, research institutes, large } \\
\text { enterprises, SMEs (5) }\end{array}$ & 6 \\
\hline Water treatment & $\begin{array}{l}\text { Natural Sciences, Engineering, } \\
\text { Social Sciences (3) }\end{array}$ & Universities, federal authorities, large enterprises, SMEs (4) & 7 \\
\hline
\end{tabular}


Evidence of the mutual understanding is that the interviewees each provided their own examples of the problems, some of them new, which allowed us to include new problem dimensions. At the end of the interview, the interviewees were invited to mention any aspects that they additionally deemed important for collaborative research.

\section{Extraction and Organization of Interview Data}

Problems and solutions that were derived from previous research were also used to develop a set of categories for the extraction and organization of the interview data. The interviewer who participated in most of the interviews also conducted the entire coding based on the transcribed interviews. The problem and solution categories were iteratively elaborated and refined throughout the coding process and the detailed analysis (see Laudel and Gläser, 2008; Gläser and Laudel, 2009). In this way, we were able to increase the granularity of our categories and, for instance, add different variants of problems as subcategories. Additionally, we found a range of new problems and solutions, which we included in our set of categories and in the subsequent analyses. Based on the problems discussed by the interviewees, we reconstructed their expectations of how a research collaboration should look, including suitable methods to solve the respective problem.

In a further step, based on the frequency of mentions by the interviewees and the ascribed importance, we weighted the problems. For this purpose, we categorized the importance of each problem mention as high/medium/low based on the explicit or implicit weighting by the interviewee. A mention of a problem ascribed with high importance was assigned five points, a problem with medium importance was given three points and low importance one point. To further emphasize a problem's ascribed relevance, we added another point for each mentioned solution that could be attributed to the same problem. Based on the resulting score, we classified the problems as highly important, somewhat important, and less important.

\section{RESULTS}

Below, we present our findings in two main parts: First, we outline the problems which researchers perceive with regard to RC (RQ1). Subsequently, we present a set of solutions which researchers perceive as useful to solve problems in collaborative research (RQ2).

\section{Seven Main Problems in RC}

As explained in the theoretical section, a RC may be seen as a club, with the specific club good in the present case being the production and use of an exclusive research opportunity. Based on this approach, we concluded that problems occur if members believe that they cannot benefit from their club membership as expected. Put differently, collaboration becomes problematic if the current practice substantially differs from participants' expectations toward RC, which can be traced back to one overarching expectation, that is, of a successful and productive collaboration. We identified seven problems, while each one affects a specific expectation toward collaboration: difference, commitment, certainty, communication, fairness, management, and personal relationships. We explain these problems and their specific differentiations, which we developed based on the empirical material, in the following. The ascribed relevance of the problems differs between various types of collaboration; the order depicted in Table 4 reflects the aggregate view of all our interviewees taken together. It is to be understood as a tentative problem hierarchy that needs further testing and validation, preferably by means of quantitative measures. New problems that have not been described yet in the literature or which could not be derived from theory were highlighted in bold.

\section{Difference Problem}

The most important problem occurs if the difference between members of a RC is perceived as too large. This problem is based on the expectation that differences within a RC should be smaller or bridged effectively. One example is different perspectives of collaborative partners, as mentioned by an engineer from a large-scale enterprise:

"Well, universities sometimes act like know-it-alls. [...] In some cases, they are not really compatible with my world. [...] Universities often have their own perspective, which is very theoretical, and one has to bring this into line and they need to be intrigued."

Our interviews revealed the following differentiation into three aspects of difference:

- differences with respect to motivations and objectives, specifically concerning the area of conflict between strategic and substantial interests

- cognitive differences, for example concerning scientific foci and styles of working

- social differences like gender or organizational diversity

The difference problem is notorious for, but not exclusive to, interdisciplinary and university-industry collaborations. A possible consequence is conflicts among collaboration partners, for example between academic members who want to publish research findings as soon as possible and corporate members who

TABLE 4 | Seven main problems of research collaboration.

\begin{tabular}{ll}
\hline High relevance & $\begin{array}{l}\text { Difference problem } \\
\text { Commitment problem } \\
\text { Certainty problem }\end{array}$ \\
Medium relevance & $\begin{array}{l}\text { Communication problem } \\
\text { Fairness problem } \\
\text { Management problem } \\
\text { Low relevance }\end{array}$ \\
& Relationship problem
\end{tabular}

Depending on the prominence and the detail the interviewees ascribed to the different problems, we assessed whether they were ranked high (three points for each mention), medium (2) or low (1 point). Additionally, we gave one point for each solution that was mentioned to tackle one of the seven problems. The resulting score allowed us to tentatively weight the problems. Highlighted problems are new problems that were developed from the empirical analysis. 
first want to claim a patent. If difference is not bridged effectively, the productivity of the collaboration may be hampered.

\section{Commitment Problem}

Collaboration in a RC can be perceived as problematic if participants consider the commitment of a substantial proportion of the research team to be too low, which is the case when they notice that others are rather focusing on their own research domain at the cost of the collective interests of the RC. This problem relates to the expectation that a higher level of commitment of all participants is necessary. Such commitment affects the RC as a whole and thus refers to the stress ratio between particular and collective interests. An example of this problem would be an exploitation of a RC in financial terms, as emphasized by an engineering researcher:

\footnotetext{
"And so, it was quite clear that some groups tried to hide behind the consortium. That means they pulled out some money for their research. I think they did many other things with this money."
}

The commitment problem can be differentiated according to the specific interests of a RC. Collaboration can thus become problematic if participants perceive that their collaborators:

- do not sufficiently ensure the intellectual coherence of the individual parts of a RC (i.e., work groups, subprojects) and cooperate beyond internal dividing lines

- do not get involved in cross-sectional tasks of a RC, e.g., a graduate school

- are committed on a short-term rather than on a longterm basis

The commitment problem is first and foremost a threat to the overarching expectation that collaborative research should be productive and meet its goals. Furthermore, it creates uncertainty because if involved partners do not deliver their contribution (in time), the whole collaborative process might be severely affected.

\section{Certainty Problem}

Although previous research suggests that uncertainty is often perceived as a scientific routine and a prerequisite for successful research (e.g., Whitley, 1984; Shrum et al., 2007), we found that a problem arises if participants perceive a lack of certainty to be a burden to the collaboration. According to our interviewees, avoidable uncertainties can lead to unforeseeable burdens. For instance, a representative of a small-enterprise tourism researcher described how it affected the collaboration when a leading partner dropped out: "If decision-makers change during the project, $[. .$.$] that is a medium-level disaster. Because$ handovers do not take place. The information from the predecessor, what he discussed with the project participants, is not available."

The underlying expectation which can be reconstructed from this problem is that uncertainties and risks in collaboration should be minimized as far as possible. Contrary to the problems mentioned above, we also found empirical evidence for the opposite situation: Rigid and strict rules and requirements can impose constraints on collaborative researchers, which can also be perceived as problematic.

The certainty problem can be differentiated based on the source of (un-)certainty:

- funding institutions, e.g., denial of a funding extension

- collaboration partners, e.g., delayed responses or premature exit

- employees or individual members, e.g., premature termination of contracts

The certainty problem is always a latent threat to the success of a RC. While some unforeseen developments may be compensated by agile leadership, other events such as the dropout of a collaboration partner can have a negative effect on the success and productivity of the collaboration. The latter case typically puts both leadership and members under substantial stress because processes are delayed or not all research goals can be met.

\section{Communication Problem}

Another problem occurs if participants of a RC perceive insufficient information and discussion between leadership and membership such that members cannot adequately participate in decisions. The underlying expectation denotes that communication processes should be of a reciprocal nature. A biologist described a situation in which members felt a lack of information from their leadership: "I think that's a reason when things don't work out. If people do not understand how decisions come about; when they feel left out because they don't have all the information."

We can differentiate this problem based on who is perceived to be responsible:

- leadership does not communicate appropriately, provides too little information and space to articulate the needs of members, does not listen or include members in discussions

- membership does not communicate appropriately, does not listen, engage in discussions or inquire about information

When members of a RC consider internal communication of either leadership or membership to be inappropriate, they refer to different aspects. Most importantly, the informational value and the choice of communication channels are mentioned. When a communication problem arises, it often leads to discontent and the impression that decision-making is intransparent. This can also negatively affect trust in leadership or in other members.

\section{Fairness Problem}

Collaboration can also become problematic if participants perceive the distribution of individual inputs and outcomes to be unfair. Fairness is conceived of as a state in which the input of each participant is in reasonable proportion to the individual outcome, and that the ratio of input and outcome is similar among all participants of a RC. According to a leading biologist at a university, fairness problems "often arise from conflict concerning authorships. Who actually has the greater intellectual stake in a joint project?" 
Empirically, we found three differentiations of this problem according to three central resources that constitute the returns of a RC:

- decisions about lead authorship in publications

- distribution of personal, financial and technical resources

- receipt of recognition and appreciation

If members perceive a lack of fairness, it typically has a detrimental effect on the personal relationships within the collaboration, and further leads to frustration among those individuals who consider themselves to be at a disadvantage.

\section{Management Problem}

The management problem occurs if members of a RC notice incompetence in their leadership. This relates to the expectation that the leadership of a RC should be qualified beyond academic expertise and able to manage the collaboration successfully and efficiently. As an IT security researcher noted self-critically about a structured program for doctoral students managed by himself and other researchers, "we overregulated [...] that a bit, I thought. [...] they had to do too much. Yet another symposium, another workshop and another seminar and this and that."

There are three differentiations of this problem, which refer to the relationship of an RC's management to the other actors involved. Accordingly, collaboration can become problematic if participants feel that researchers in leading positions:

- take advantage of their status rather than focusing on the interests of the RC as a whole

- tend to restrict the autonomy of individual members too much or apply a management style without guidance

- are not capable of dealing flexibly with the requirements laid out by the funding institutions

According to our interviewees, the management problem can aggravate other problems. For instance, when the management of a RC is not sufficiently competent to take steps to reduce a sense of unfairness in the RC or to bridge cognitive differences effectively, it can be detrimental to the success of collaboration and also lead to frustration among members.

TABLE 5 | Twelve solutions to collaboration problems.

\begin{tabular}{|c|c|c|}
\hline Solution & Description & $\begin{array}{l}\text { Exemplary problems to } \\
\text { address }\end{array}$ \\
\hline \multicolumn{3}{|l|}{ Target: Participants } \\
\hline $\begin{array}{l}\text { 1. Selection of Participants } \\
\text { (proactive) }\end{array}$ & $\begin{array}{l}\text { Selection based on proven ability to collaborate, e.g., previous collaboration partners, as a } \\
\text { means to reduce risks for the collaboration and increase time efficiency }\end{array}$ & $\begin{array}{l}\text { Commitment problem, } \\
\text { certainty problem }\end{array}$ \\
\hline $\begin{array}{l}\text { 2. Motivation } \\
\text { (reactive) }\end{array}$ & $\begin{array}{l}\text { Motivation and appreciation of all participants, from principal investigators to doctoral } \\
\text { students, e.g., by providing incentives or appealing to the individual interests of the } \\
\text { participants }\end{array}$ & $\begin{array}{l}\text { Commitment problem, } \\
\text { fairness problem }\end{array}$ \\
\hline $\begin{array}{l}\text { 3. Leadership personality } \\
\text { (proactive) }\end{array}$ & $\begin{array}{l}\text { Integrative and competent personality for leadership combining experience, authority and } \\
\text { pronounced communicative capabilities }\end{array}$ & $\begin{array}{l}\text { Management problem, } \\
\text { relationship problem }\end{array}$ \\
\hline $\begin{array}{l}\text { 4. Personal relationships } \\
\text { (proactive) }\end{array}$ & Trust-building by maintaining personal relationships, e.g., informal meetings & $\begin{array}{l}\text { Relationship problem, } \\
\text { communication problem }\end{array}$ \\
\hline $\begin{array}{l}\text { Target: Cognitive basis } \\
\text { 5. Research program } \\
\text { (proactive) }\end{array}$ & $\begin{array}{l}\text { Development of a research program that integrates the interests and competencies of all } \\
\text { participants, including a joint definition of research goals, to secure a high commitment by } \\
\text { all participants }\end{array}$ & $\begin{array}{l}\text { Difference problem, } \\
\text { commitment problem }\end{array}$ \\
\hline $\begin{array}{l}\text { 6. Common ground } \\
\text { (proactive) }\end{array}$ & $\begin{array}{l}\text { Creating common ground, e.g., through collaborative verbalization of a self-concept } \\
\text { (common identity), methodological norms, or a compelling research idea inspiring the joint } \\
\text { research, e.g., in interdisciplinary contexts }\end{array}$ & $\begin{array}{l}\text { Commitment problem, } \\
\text { difference problem }\end{array}$ \\
\hline $\begin{array}{l}\text { 7. Set of rules } \\
\text { (proactive) }\end{array}$ & $\begin{array}{l}\text { Joint development of a codified set of rules for the collaboration incl. dos and don'ts, as a } \\
\text { means to both reduce and resolve conflicts, e.g., with regard to disclosure of results }\end{array}$ & $\begin{array}{l}\text { Fairness problem, certainty } \\
\text { problem }\end{array}$ \\
\hline \multicolumn{3}{|c|}{ Target: Interaction and communication } \\
\hline $\begin{array}{l}\text { 8. Appropriate style of leadership } \\
\text { (proactive) }\end{array}$ & $\begin{array}{l}\text { Leadership style that is adjusted to the type of research collaboration, ranging from } \\
\text { participatory (high autonomy of members) to centralized leadership (low autonomy), } \\
\text { depending on both the size of the } \mathrm{RC} \text { and the organizational cultures involved }\end{array}$ & $\begin{array}{l}\text { Management problem, } \\
\text { difference problem }\end{array}$ \\
\hline $\begin{array}{l}\text { 9. Communication space } \\
\text { (proactive) }\end{array}$ & $\begin{array}{l}\text { Creating and using a shared communication space, e.g., online collaboration tools but } \\
\text { also offline venues for in-person exchange, to increase transparency and create } \\
\text { opportunities for low-threshold participation }\end{array}$ & $\begin{array}{l}\text { Communication problem, } \\
\text { fairness problem }\end{array}$ \\
\hline $\begin{array}{l}\text { 10. Handling of conflicts } \\
\text { (reactive) }\end{array}$ & $\begin{array}{l}\text { Constructive handling of conflicts by explicating and integrating e.g., different research } \\
\text { interests, disciplinary perspectives or methodological standards }\end{array}$ & $\begin{array}{l}\text { Difference problem, } \\
\text { relationship problem }\end{array}$ \\
\hline $\begin{array}{l}\text { 11. Synchronization } \\
\text { (proactive) }\end{array}$ & $\begin{array}{l}\text { Synchronization of processes through the determination of deadlines, tasks, and } \\
\text { responsibilities }\end{array}$ & $\begin{array}{l}\text { Certainty problem, } \\
\text { management problem }\end{array}$ \\
\hline $\begin{array}{l}\text { 12. Evaluation } \\
\text { (reactive) }\end{array}$ & $\begin{array}{l}\text { Continuous evaluation of collaboration, including the detection of conflicts or problems } \\
\text { through listening to the needs and concerns of members and control of target } \\
\text { achievement }\end{array}$ & $\begin{array}{l}\text { Management problem, } \\
\text { commitment problem }\end{array}$ \\
\hline
\end{tabular}

Highlighted solutions are new solutions developed from the empirical analysis. 


\section{Relationship Problem}

Collaboration can also be perceived as problematic if personal relationships among participants tend to strain and hinder work processes rather than supporting and stimulating research. As a medical researcher put it, "The biggest problem is when you can't stand people in a research network. [...] Because would you sit together with someone [...] if you didn't like the person at all? You won't sit down in the evening with him in a pub and brainstorm over dinner."

From this problem, we can reconstruct participants' expectation that personal relationships should be more beneficial or at least less detrimental to collaborative research. We can differentiate this problem into two contrasting variants. Relationship problems occur if participants perceive:

- personal relationships as too tight and demanding

- social distances as too great, which does not allow for personal relationships based on mutual liking

Some of our interviewees stated that in the case of problematic social relationships, collaboration might be less productive, while others did not attribute particular relevance to this problem.

\section{Solutions to Problems in RC: Three Perspectives on Self-Governance}

To identify solutions to problems that researchers perceive as useful, we sought to carve out what can be done to meet the overarching expectation of a productive and successful collaboration. To draw conclusions about solutions that are generalizable beyond specific contexts, the participants' expectations and experiences are paramount in as much as they act as hinges between problems and solutions: Collaboration becomes problematic if the current practice deviates substantially from expectations. Thus, the function of solutions is to converge the current practice toward the expectations of participants.

At this point, we need to emphasize that the basic principle of solutions is neither a laissez-faire policy nor governance from the outside or from superior institutions (e.g., university or politics). Rather, based on the insights of commons theory, we suggested self-governance as the basic principle to address problems in collaborative research. The most important question refers to the rules themselves, that is, what can be done to solve the problems outlined above. Two further questions are also of relevance, albeit less so: Who is responsible for solving collaboration problems? And when should collaboration problems be addressed?

\section{What? 12 Preferred Solutions for Self-Governance}

From our empirical insights, we were able to extract 12 solutions, which are regarded as more or less suitable to address collaboration problems and to converge the current practice toward the participants' expectations. We analyzed the interviewees' answers and grouped their suggestions according to the central targets which we reconstructed from the mentioned solutions: (1) the participants of a RC and their composition, (2) the cognitive basis of a RC, i.e., participants' shared knowledge, standards, and values, and (3) interaction and communication within a RC. The resulting set is summarized in Table 5. New solutions that have not been described as such in the previous literature or could not be derived from theory are highlighted in bold letters.

This eclectic set of possible solutions to collaboration problems represents the rules for self-governance of a RC. However, two central points need to be emphasized: First, our interviewees' experience shows that none of the problems can be solved through one single solution, and none of the solutions accounts for one specific problem. Rather, every single problem requires a balanced set of different solutions that is based on extensive negotiations between all affected participants in order to reflect their individual viewpoints, needs, and preferences. For instance, the difference problem can be addressed on a cognitive basis by a research program that integrates the various disciplinary perspectives represented in a collaboration, for instance by integrating the interests and competencies of all participants, including a joint definition of research goals (Solution 5). The same problem, however, can also be addressed on an interactional level by creating opportunities to strengthen social ties within or outside the typical venues of the collaboration (Solution 4). Both solutions can of course also be applied in a complementary manner-a principle that is often stressed by our interviewees, as one solution is often not considered sufficient for tackling a problem effectively. Nevertheless, we also found some general tendencies during the course of our interview analyses: For example, as solutions to the commitment problem, Solutions 1 and 6 (selection of participants and common ground) were predominantly mentioned, while for the management problem, Solutions 8 and 11 (appropriate style of leadership and synchronization) were often emphasized.

Another central point relates to the fact that the listed solutions are not equally applicable to all kinds of RCs. This specifically becomes apparent through Solution 8, for which we recommend, based on our interviews, different variations depending on the type of collaboration. But it also affects the selection of solutions in general. While for one RC an occurring commitment problem might be solvable by establishing a common ground (Solution 6), for another RC the strengthening of personal relationships might be more efficient (Solution 4).

Taken together, these two points underline that the varying conditions need to be considered. On the macro level, this mainly affects the societal environment and science policy regulations. Financial resources and university politics are examples of relevant conditions on the meso level. Lastly, on the micro level, different characteristics of the researchers involved in collaboration have been mentioned, for example different styles of working or motivations. Moreover, the phase of the collaboration needs to be taken into account when selecting solutions. Problems that occur in advance (i.e., while working on the application) call for different solutions than problems that occur during or after the collaboration. For example, the commitment problem might be solved by selecting reliable participants in advance (Solution 1), while it might be advisable to solve this problem by creating a common ground (Solution 6) once the collaboration has started. 


\section{Who? Actors of Self-Governance}

With respect to the question of who is responsible for solving collaboration problems, we cannot extrapolate general recommendations from our interviews. Rather, different constellations along a spectrum are possible, ranging from a pronounced focus on leadership to the involvement of all participants. The former type is recommended for RCs with centralized leadership, often to be found in university-industry collaborations. Meanwhile, university-only RCs tend toward more participatory forms of leadership. A variant of this approach, suitable for larger collaborations, is an elected steering committee representing all members. Due to the heterogeneity of participants in a RC, there are always different perspectives involved, which leads to different ideas of who should be responsible. Therefore, like the solutions themselves, this needs to be carefully negotiated within the self-regulatory framework of RCs. The level of consensus between the participants then results in the decision about how urgently which actors need to take action.

\section{When? Strategies of Self-Governance}

Finally, we aim to answer the question of when collaboration problems should be solved, which relates to self-governance as a process. Primarily, this concerns different strategies and we can basically differentiate between a reactive and a proactive strategy: Problems can be addressed once they occur, for example motivating participants (Solution 2) might help to solve a commitment problem that develops over time. Alternatively, problems can be foreseen and possibly prevented, for example the relationship problem might be averted by selecting suitable participants for a research team (Solution 1) from the very outset. From our interview data, we cannot derive a specific pattern. Instead, there are hybrid forms of both strategies with a slight dominance of the proactive one.

\section{DISCUSSION}

\section{Summary of Our Findings}

The aim of this study was to answer the following questions:

RQ1: Which problems do researchers perceive with regard to RC?

RQ2: Which problem solutions do researchers within RC perceive as useful?

To answer these questions, we relied on a theoretical framework that combined two micro-oriented approaches: club theory and commons theory. Based on the notion that problems are perceived where participants' expectations toward the collaboration are not met, we found that problems may occur in RCs with respect to seven aspects: commitment, difference, commitment, certainty, communication, fairness, management, and personal relationships. The three most important problems are the difference problem, which results from too large differences with respect to the composition of a RC, the commitment problem, which occurs if participants focus on their individual interests at the expense of collective interests, and the certainty problem, which is caused by unpredictable uncertainties and risks in collaboration. In many cases, these problems co-occur and mutually cause each other. The management problem, for example, can exacerbate an existing commitment and/or a certainty problem. Furthermore, the problems and their particular manifestation depend on the specific context, for example the phase of collaboration or the type of partners involved.

Based on our empirical insights, we developed a set of 12 solutions which have three targets: the participants of a RC, the cognitive basis of a RC, and the interaction and communication within a RC. These solutions may, from the interviewees' perspective, help to address or prevent collaboration problems. Their central function lies in the convergence of the current practice toward the expectations of participants. Based on this understanding of problems and solutions, it is possible to realize self-governance as an effective way of organizing RCs, defined as research units working on a joint project.

\section{Theoretical and Practical Contributions}

Several of the problems and solutions we identified resonate with previous scholarship on collaborative research. With respect to collaboration problems, for example, various scholars have emphasized that differences among participants (e.g., Barnes et al., 2002; Bozeman et al., 2016; Volk, 2021) or a lack of commitment of participants (e.g., Barnes et al., 2002; Gaskill et al., 2003; Bozeman et al., 2016) can be obstacles to joint research, which resembles what we called the difference and the commitment problem. Previous research has also mentioned some of the solutions we suggested, such as fostering trust through good personal relationships (e.g., Chompalov and Shrum, 1999; Shrum et al., 2001, 2007; Bruneel et al., 2010) or the assignment of a competent leadership (e.g., Vonortas and Spivack, 2006; Schützenmeister, 2010; Volk, 2021). However, to the best of our knowledge, no previous study has provided a similarly systematic picture. Furthermore, our study differentiated and expanded our knowledge of collaboration problems and ways in which to solve them. We were able to advance an in-depth understanding of problems in RCs and identify different dimensions of each problem. Moreover, we also identified uncertainty as a problem which, probably because it has been suggested as a common standard of research (e.g., Whitley, 1984; Shrum et al., 2007), has received barely any attention in the context of collaborative research so far. Furthermore, we strengthened the importance of problems that have been mentioned before and specified their implications, for example with respect to the fairness problem. With regard to a self-governance perspective, we found several new solutions (see Table 5), such as the development of an integrative (Solution 5) creating cognitive common ground between participants (Solution 6), and the continuous evaluation of the collaboration (Solution 12).

Considering these achievements, we conclude that the microtheoretical lens and the unique combination of club theory and commons theory is a useful and productive framework for the analysis of RC. In particular, club theory helped us to identify the problems that result from a target-oriented association of researchers and to strengthen problems which had not received much attention before, for example, the fairness problem. 
Commons theory allowed us to establish a useful framework of academic self-governance that is sustainable and sensitive to the specific conditions of collaborative research. Thanks to their combination, these approaches helped us to reduce the tension between individual and collective interests. Furthermore, both theoretical approaches, and more importantly, their combination sets a clear focus on the interaction of researchers as both basis for problems and solutions. This understanding of governing collaborative research is consistent with current developments in science and technology studies: Using the term "tentative governance," scholars have most recently suggested to rely on a form of governance that is dynamic, flexible, and sensitive to the respective conditions and requirements of the scientific environment rather than on definite and persistent forms (Kuhlmann et al., 2019). Additionally, our study lends support to the assumption that individual expectations influence not only the perception but also the relevance of collaboration problems and the preference for specific solutions. Including this subjective aspect might, in our view, be a relevant advancement for both theories upon which we relied.

Furthermore, previous research mainly focused on one type of RC (e.g., university-industry collaboration) or specific problems and solutions. As we believe that the presented catalogs are generalizable beyond single contexts while at the same time being concise, they promote a consistent systematization of this field and may be used as heuristics for further empirical studies on collaborative research (e.g., surveys). In addition, they enhance our understanding about the success or failure of collaborative research and may serve as a foundation for practical conclusions, for example as guidelines for consulting and coaching. Lastly, the problems and solutions we found for RCs may also inform similar studies on other forms of scientific collaboration such as co-authorship or cooperation within scientific organizations.

\section{Limitations and Gaps for Future Research}

A first limitation refers to the fact that we did not consider objective parameters for the success and performance of RCs, such as bibliometric measures. Rather, the problems we identified were solely based on the participants' experiences and perceptions, and the solutions they suggested cannot be evaluated with respect to their objective effectiveness. Thus, further validation is needed. Second, because our sample included (purportedly) functioning RCs only, there might be more important or more serious problems in collaborative research that our catalog is missing. Third, because we took a general look at problems and solutions we did not differentiate between different types of RCs, for example in terms of their size (i.e., number of researchers and organizations) and constellation (university-industry vs. academic-only), the type of funding, or the phase of collaboration. The latter one specifically has important consequences for collaboration problems as well as solutions (Volk, 2021). And it may well be the case that some problems only occur in specific forms of RCs and/or vary in their intensity depending on the type of RC. Fourth, while we emphasized that the varying conditions of collaboration are relevant, we did not investigate these conditions in depth. Therefore, further empirical studies are needed in order to identify the relationships between the conditions of collaborative research, potential problems, and useful solutions. Fifth, we focused on German RCs in our study. Although we assume that the identified problems also occur in RCs in other countries and cultures and that the solutions are similarly applicable, further research is needed to ensure the generalizability of our catalogs beyond this and a solely national context. Sixth, we focused on the viewpoints of speakers, principal investigators, and coordinators. Our sample did not include further members of RCs such as postdocs and doctoral students, which might have led to additional insights.

\section{CONCLUSION}

Our study offers a theoretically and empirically informed, systematic framework for understanding and addressing problems in collaborative research. This framework may help to maximize the prospects of success for all sorts of scientific collaboration. However, our study is only a starting point. We thus hope to inspire further research that refines and extends our insights. Most specifically, future studies, for instance quantitative surveys, can apply and validate our catalogs of problems and solutions with respect to collaboration in different disciplines and countries, and to different sizes and composition of RCs, in order to verify whether researchers are able to prevent problems and ultimately the failure of collaboration as far as possible.

\section{DATA AVAILABILITY STATEMENT}

In April 2022 our data will be published under the following doi: 10.21249/DZHW:decquali:1.0.0.

\section{ETHICS STATEMENT}

Ethical review and approval was not required for the study on human participants in accordance with the local legislation and institutional requirements. The patients/participants provided their written informed consent to participate in this study.

\section{AUTHOR CONTRIBUTIONS}

FM and GV contributed to conception and design of the study. FM organized the database and performed the analysis. FM and CW wrote the first draft of the manuscript. All authors contributed to manuscript revision, read, and approved the submitted version.

\section{FUNDING}

This research was supported by the German Federal Ministry of Education and Research (Grant Number: M527800). 


\section{ACKNOWLEDGMENTS}

We would like to thank Michael Baurmann, Monika Jungbauer-Gans, Ole Kelm, Charlotte Löb, and Martin Reinhart for their valuable comments on earlier versions of this manuscript and Aliakbar Akbaritabar for encouraging

\section{REFERENCES}

Abramo, G., D’Angelo, C. A., and Murgia, G. (2013). Gender differences in research collaboration. J. Informetrics 7, 811-822. doi: 10.1016/j.joi.2013. 07.002

Adams, J. D., Black, G. C., Clemmons, J. R., and Stephan, P. E. (2005). Scientific teams and institutional collaborations: evidence from U.S. universities, 1981-1999. Res. Policy 34, 259-285. doi: 10.1016/j.respol.2005. 01.014

Adler, N., Elmquist, M., and Norrgren, F. (2009). The challenge of managing boundary-spanning research activities: experiences from the Swedish context. Res. Policy 38, 1136-1149. doi: 10.1016/j.respol.2009.05.001

Akkerman, S., Admiraal, W., and Simons, R. J. (2012). Unity and diversity in a collaborative research project. Cult. Psychol. 18, 227-252. doi: $10.1177 / 1354067 \mathrm{X} 11434835$

Ankrah, S., and AL-Tabbaa, O. (2015). Universities-industry collaboration: a systematic review. Scand. J. Manag. 31, 387-408. doi: 10.1016/j.scaman.2015. 02.003

Bammer, G. (2008). Enhancing research collaborations: three key management challenges. Res. Policy 37, 875-887. doi: 10.1016/j.respol.2008.03.004

Barnes, T., Pashby, I., and Gibbons, A. (2002). Effective university-industry interaction: a multi-case evaluation of collaborative R\&D projects. Eur. Manag. J. 20, 272-285. doi: 10.1016/S0263-2373(02)00044-0

Baurmann, M., and Brennan, G. (2016). "On virtue economics," in Economics and the Virtues: Building a New Moral Foundation, eds J. A. Baker, and M. D. White (Oxford: Oxford University Press), 119-140. doi: 10.1093/acprof:oso/9780198701392.003.0007

Baurmann, M., and Vowe, G. (2014). Wie lassen sich Kooperationsprobleme in Forschungsverbünden lösen? Bielefeld: Forschung. 73-84.

Beaver, D. D. (2013). The many faces of collaboration and teamwork in scientific research: Updated reflections on scientific collaboration. Collnet J. Scientometrics Inf. Manag. 7, 45-54. doi: 10.1080/09737766.2013.80 2629

Begun, A. L., Berger, L. K., Otto-Salaj, L. L., and Rose, S. J. (2010). Developing effective social work university - community research collaborations. Soc. Work 55, 54-62. doi: 10.1093/sw/55.1.54

Bendersky, C., and Hays, N. A. (2012). Status conflict in groups. Organ. Sci. 23, 323-340. doi: 10.1287/orsc. 1110.0734

Berlemann, M., and Haucap, J. (2015). Which factors drive the decision to opt out of individual research rankings? An empirical study of academic resistance to change. Res. Policy 44, 1108-1115. doi: 10.1016/j.respol.2014. 12.002

Bicchieri, C. (2006). The Grammar of Society: The Nature and Dynamics of Social Norms. Cambridge: Cambridge University Press. doi: 10.1017/CBO9780511616037

Bjerregaard, T. (2009). Universities-industry collaboration strategies: a micro-level perspective. Eur. J. Innov. Manag. 12, 161-176. doi: 10.1108/14601060910953951

Bjerregaard, T. (2010). Industry and academia in convergence: microinstitutional dimensions of R\&D collaboration. Technovation 30, 100-108. doi: 10.1016/j.technovation.2009.11.002

Bora, A. (2012). "Wissenschaft und Politik: von Steuerung über Governance zu Regulierung," in Handbuch Wissenschaftssoziologie, eds S. Maasen, M. Kaiser, M. Reinhart, and B. Sutter (Wiesbaden: Springer), 341-353. doi: 10.1007/978-3-531-18918-5_27

Bozeman, B., Fay, D., and Slade, C. P. (2013). Research collaboration in universities and academic entrepreneurship: the-state-of-the-art. J. Technol. Transf. 38, 1-67. doi: 10.1007/s10961-012-9281-8 us to submit our manuscript to this Research Topic. We would also like to thank Xue Gao and Kenneth Evans for their helpful reviews and Jennifer Dusdal for her efforts as Editor of this Research Topic. Furthermore, we thank Jana Huneke for her support during the empirical study.

Bozeman, B., and Gaughan, M. (2011). How do men and women differ in research collaborations? An analysis of the collaborative motives and strategies of academic researchers. Res. Policy 40, 1393-1402. doi: 10.1016/j.respol.2011.07.002

Bozeman, B., Gaughan, M., Youtie, J., Slade, C. P., and Rimes, H. (2016). Research collaboration experiences, good and bad: dispatches from the front lines. Sci. Public Policy 43, 226-244. doi: 10.1093/scipol/scv035

Bozeman, B., and Youtie, J. (2017). The Strength in Numbers: The New Science of Team Science. Oxford: Princeton University Press. doi: 10.2307/j.ctvc $77 \mathrm{bn} 7$

Bruneel, J., D'Este, P., and Salter, A. (2010). Investigating the factors that diminish the barriers to university-industry collaboration. Res. Policy 39, 858-868. doi: 10.1016/j.respol.2010.03.006

Buchanan, J. M. (1965). An economic theory of clubs. Economica 32, 1-14. doi: $10.2307 / 2552442$

Chapman, G., Lucena, A., and Afcha, S. (2018). R\&D subsidies \& external collaborative breadth: differential gains and the role of collaboration experience. Res. Policy 47, 623-636. doi: 10.1016/j.respol.2018. 01.009

Chompalov, I., and Shrum, W. (1999). Institutional collaboration in science: a typology of technological practice. Sci. Technol. Hum. Values 24, 338-372. doi: 10.1177/016224399902400302

Cohen, S. S., Luekens, C., and McCorkle, R. (2011). Lessons learned in research, collaboration, and dissemination in a national institute of nursing research-funded research center. J. Prof. Nurs. 27, 153-160. doi: 10.1016/j.profnurs.2010.10.009

Cornes, R., and Sandler, T. (1996). The Theory of Externalities, Public Goods, and Club Goods. Cambridge: Cambridge University Press. doi: 10.1017/CBO9781139174312

Costa, M. R. (2014). The dynamics of social capital in scientific collaboration networks. Proc. Am. Soc. Inf. Sci. Technol. 51, 1-4. doi: 10.1002/meet.2014.14505101137

Cummings, J. N., and Kiesler, S. (2007). Coordination costs and project outcomes in multi-university collaborations. Res. Policy 36, 1620-1634. doi: 10.1016/j.respol.2007.09.001

Cummings, J. N., and Kiesler, S. (2008). "Who collaborates successfully? Prior experience reduces collaboration barriers in distributed interdisciplinary research," in CSCW '08 Proceedings of the 2008 ACM Conference on Computer Supported Cooperative Work, ed B. Begole and D. W. McDonald (New York: ACM), 437-446. doi: 10.1145/1460563.1460633

Cummings, J. N., Kiesler, S., Bosagh Zadeh, R., and Balakrishnan, A. D. (2013). Group heterogeneity increases the risks of large group size: a longitudinal study of productivity in research groups. Psychol. Sci. 24, 880-890. doi: $10.1177 / 0956797612463082$

Currie-Alder, B., Arvanitis, R., and Hanafi, S. (2018). Research in Arabicspeaking countries: Funding competitions, international collaboration, and career incentives. Sci. Public Policy 45, 74-82. doi: 10.1093/scipol/scx048

Dusdal, J., and Powell, J. J. W. (2021). Benefits, motivations, and challenges of international collaborative research: a sociology of science case study. Sci. Public Policy 48, 235-245. doi: 10.1093/scipol/scab010

Ettorre, E. (2000). Recognizing diversity and group processes in international, collaborative research work: A case study. Soc. Policy Admin. 34, 392-407. doi: 10.1111/1467-9515.00199

Garcia, R., Araújo, V., Mascarini, S., Santos, E. G., and Costa, A. R. (2019). How the benefits, results and barriers of collaboration affect university engagement with Industry. Sci. Public Policy 46, 347-357. doi: 10.1093/scipol/scy062

Gaskill, D., Morrison, P., Sanders, F., Forster, E., Edwards, H., McClure, S., et al. (2003). University and industry partnerships: Lessons from collaborative 
research. Int. J. Nurs. Pract. 9, 347-355. doi: 10.1046/j.1440-172X.2003.00 448.x

Gläser, J. (2019). "How can governance change research content? Linking science policy studies to the sociology of science," in Handbook on Science and Public Policy, eds. D. Simon, S. Kuhlmann, J. Stamm and W. Canzler (Cheltenham, UK: Edward Elgar Publishing), 419-447. doi: 10.4337/9781784715946.0 0033

Gläser, J., and Laudel, G. (2009). Experteninterviews und qualitative Inhaltsanalyse als Instrumente rekonstruierender Untersuchungen. Wiesbaden: VS Verlag. doi: 10.1007/978-3-531-91538-8

Goddard, T., Cranston, N., and Billot, J. (2006). Making it work: Identifying the challenges of collaborative international research. Int. Electron. J. Leadersh. Learn. 10, 1-5. https://journals.library.ualberta.ca/iejll/index.php/iejll/article/ view/611/273

Gross, C., Jungbauer-Gans, M., and Nisic, N. (2017). "Cooperation and career chances in science," in Social dilemmas, institutions, and the evolution of cooperation, ed B. Jann and W. Przepiorka (Berlin, Germany: De Gruyter), 165-188. doi: 10.1515/9783110472974-009

Hackett, E. J. (2005). Essential tensions: identity, control, and risk in research. Soc. Stud. Sci. 35, 787-826. doi: 10.1177/0306312705056045

Hackett, E. J., Parker, J. N., Vermeulen, N., and Penders, B. (2017). "The social and epistemic organization of scientific work," in The Handbook of Science and Technology Studies, eds U. Felt, R. Fouché, C. A. Miller, and L. Smith-Doerr (Cambridge, MA: The MIT Press), 733-764.

Haeussler, C., and Sauermann, H. (2020). Division of labor in collaborative knowledge production: the role of team size and interdisciplinarity. Res. Policy 49:103987. doi: 10.1016/j.respol.2020.103987

Hara, N., Solomon, P., Kim, S.-L., and Sonnenwald, D. H. (2003). An emerging view of scientific collaboration: Scientists' perspectives on collaboration and factors that impact collaboration. J. Am. Soc. Inf. Sci. Technol. 54, 952-965. doi: 10.1002/asi.10291

Heller, C. A., and Michelassi, F. (2012). Forging successful interdisciplinary research collaborations: a nationwide survey of departments of surgery. Surgery 151, 502-509. doi: 10.1016/j.surg.2011.09.034

Hewitt-Dundas, N., Gkypali, A., and Roper, S. (2019). Does learning from prior collaboration help firms to overcome the 'two-worlds' paradox in university-business collaboration? Res. Policy 48, 1310-1322. doi: 10.1016/j.respol.2019.01.016

Hoecht, A. (2004). Control in collaborative research and technology development. J. Managerial Psychol. 19, 218-234. doi: 10.1108/02683940410527720

Holl, A., and Rama, R. (2019). Local cooperation for innovation in ICT-Domestic Groups with collaborations for innovation abroad and foreign subsidiaries. Sci. Public Policy 46, 599-610. doi: 10.1093/scipol/scz013

Jackson, J. W. (2011). Intragroup cooperation as a function of group performance and group identity. Group Dyn. 15, 343-356. doi: 10.1037/a0024575

Jeffrey, P. (2003). Smoothing the waters: observations on the process of cross-disciplinary research Collaboration. Soc. Stud. Sci. 33, 539-562. doi: $10.1177 / 0306312703334003$

Jeong, S., and Choi, J. Y. (2015). Collaborative research for academic knowledge creation: How team characteristics, motivation, and processes influence research impact. Sci. Public Policy 42, 460-473. doi: 10.1093/scipol/scu067

Johann, D., Velicu, A., and Rauhut, H. (2020). Ko-Autorschaft und wissenschaftliche Publikationen: Kooperationen und Konflikte. Forschung und Lehre 27, 506-507. doi: 10.5167/uzh-188417

Katz, J. S., and Martin, B. R. (1997). What is research collaboration? Res. Policy 26, 1-18. doi: 10.1016/S0048-7333(96)00917-1

Kezar, A. (2005). Redesigning for collaboration within higher education institutions: an exploration into the developmental process. Res. High. Educ. 46, 831-860. doi: 10.1007/s11162-004-6227-5

Kosmützky, A. (2018). A two-sided medal: on the complexity of international comparative and collaborative team research. Higher Educ Q 72, 314-331. doi: 10.1111/hequ.12156

Kuhlmann, S., Stegmaier, P., and Konrad, K. (2019). The tentative governance of emerging science and technology-A conceptual introduction. Res. Policy 48, 1091-1097. doi: 10.1016/j.respol.2019.01.006

Laudel, G., and Gläser, J. (2008). From apprentice to colleague: the metamorphosis of early career researchers. High. Educ. 55, 387-406. doi: $10.1007 /$ s10734-007-9063-7
Lee, T. W., and Mitchell, T. R. (2011). Working in research teams: lessons from personal experiences. Manag. Organ. Rev. 7, 461-469. doi: 10.1111/j.1740-8784.2011.00224.x

Lewis, J. M., Ross, S., and Holden, T. (2012). The how and why of academic collaboration: disciplinary differences and policy implications. High. Educ. 64, 693-708. doi: 10.1007/s10734-012-9521-8

Liang, X., and Liu, A. M. M. (2018). The evolution of government sponsored collaboration network and its impact on innovation: a bibliometric analysis in the Chinese solar PV sector. Res. Policy 47, 1295-1308. doi: 10.1016/j.respol.2018.04.012

Luo, A., and Omollo, K. L. (2013). Lessons learned about coordinating academic partnerships from an international network for health education. J. Assoc. Am. Med. Colleges 88, 1658-1664. doi: 10.1097/ACM.0b013e3182a $7 \mathrm{f} 815$

Mascarenhas, C., Ferreira, J. J., and Marques, C. (2018). University-industry cooperation: a systematic literature review and research agenda. Sci. Public Policy 45, 708-718. doi: 10.1093/scipol/scy003

Mirnezami, S. R., Beaudry, C., and Tahmooresnejad, L. (2020). The effect of collaboration with top-funded scholars on scientific production. Sci. Public Policy 47, 219-234. doi: 10.1093/scipol/scz060

Morandi, V. (2013). The management of industry-university joint research projects: how do partners coordinate and control R\&D activities? J. Technol. Transf. 38, 69-92. doi: 10.1007/s10961-011-9228-5

Muriithi, P., Horner, D., Pemberton, L., and Wao, H. (2018). Factors influencing research collaborations in Kenyan universities. Res. Policy 47, 88-97. doi: 10.1016/j.respol.2017.10.002

Ostrom, E. (1990). Governing the Commons: The Evolution of Institutions for Collective Action. Cambridge: Cambridge University Press. doi: 10.1017/CBO9780511807763

Ostrom, E. (1999). Coping with the tragedy of the commons. Annu. Rev. Polit. Sci. 2, 493-535. doi: 10.1146/annurev.polisci.2.1.493

Ostrom, E. (2005). "Towards a behavioral theory linking trust, reciprocity, and reputation," in Trust and Reciprocity: Interdisciplinary Lessons From Experimental Research, eds E. Ostrom, and J. Walker (New York: Russell Sage Foundation), 19-79.

Ostrom, E., Gardner, R. J., and Walker, J. (1994). Rules, Games, and Common-Pool Resources. Ann Arbor, MI: University of Michigan Press. doi: 10.3998/mpub.9739

Porac, J. F., Wade, J. B., Fischer, H. M., Brown, J., Kanfer, A., and Bowker, G. (2004). Human capital heterogeneity, collaborative relationships, and publication patterns in a multidisciplinary scientific alliance: a comparative case study of two scientific teams. Res. Policy 33, 661-678. doi: 10.1016/j.respol.2004.01.007

Prakash, A., and Potoski, M. (2009). Voluntary Programs: A Club Theory Perspective. Cambridge, MA: MIT Press.

Raadgever, G. T., Mostert, E., and van de Giesen, N. C. (2012). Learning from collaborative research in water management practice. Water Resour. Manag. 26, 3251-3266. doi: 10.1007/s11269-012-0070-9

Sacco, T. (2020). The good, the bad, and the ugly: dimensions of success and failure in research Collaboration. Sociol Forum 35, 488-510. doi: 10.1111/socf. 12591

Sandler, T., and Tschirhart, J. (1997). Club theory: thirty years later. Public Choice 93, 335-355. doi: 10.1023/A:1017952723093

Scanlon, E., Anastopoulou, S., Conole, G., and Twiner, A. (2019). Interdisciplinary working methods: reflections based on technology-enhanced learning (TEL). Front. Educ. 4:134. doi: 10.3389/feduc.2019.00134

Schützenmeister, F. (2010). University Research Management: An Exploratory Literature Review. Berkeley: Institute of European Studies, UC Berkeley.

Segalla, M. (1998). Factors for the success or failure of international teams. J. Managerial Psychol. 13, 133-136. doi: 10.1108/026839498102 14841

Shrum, W., Chompalov, I., and Genuth, J. (2001). Trust, conflict and performance in scientific collaborations. Soc. Stud. Sci. 31, 681-730. doi: 10.1177/030631201031005002

Shrum, W., Chompalov, I., and Genuth, J. (2007). Structures of Scientific Collaboration. Cambridge, MA: MIT Press. doi: 10.7551/mitpress/7461.001.0001

van Laerhoven, F., and Ostrom, E. (2007). Traditions and trends in the study of the commons. Int. J. Commons 1, 3-28. doi: 10.18352/ijc.76 
Vicens, Q., and Bourne, P. E. (2007). Ten simple rules for a successful collaboration. Comput. Biol. 3, 335-336. doi: 10.1371/journal.pcbi.0030044

Vick, T. E., and Robertson, M. (2018). A systematic literature review of UK university-industry collaboration for knowledge transfer: a future research agenda. Sci. Public Policy 45, 579-590. doi: 10.1093/scipol/scx086

Volk, S. C. (2021). Comparative Communication Research: A Study of the Conceptual, Methodological, and Social Challenges of International Collaborative Studies in Communication Science. New York, NY: Springer VS.

Vonortas, N. S., and Spivack, R. N. (2006). Managing large research partnerships: examples from the advanced technology program's information infrastructure for healthcare program. Technovation 26, 1101-1110. doi: 10.1016/j.technovation.2005.08.011

Wagner, C. S. (2019). "Global science for global challenges," in Handbook on Science and Public Policy, ed D. Simon, S. Kuhlmann, J. Stamm and W. Canzler (Cheltenham, UK: Edward Elgar Publishing), 92-103.

Wagner, C. S., Whetsell, T. A., and Mukherjee, S. (2019). International research collaboration: novelty, conventionality, and atypicality in knowledge Recombination. Res. Policy 48, 1260-1270. doi: 10.1016/j.respol.2019.01.002

Whitley, R. D. (1984). The Intellectual and Social Organization of the Sciences. Oxford: Clarendon Press.

Wöhlert, R. (2020). Communication in international collaborative research teams: a review of the state of the art and open research questions. SCM Stud. Commun. Media 9, 151-217. doi: 10.5771/2192-4007-2020-2-151

Yang, L. (2018). Collaborative knowledge-driven governance: types and mechanisms of collaboration between science, social science, and local knowledge. Sci. Public Policy 45, 53-73. doi: 10.1093/scipol/scx 047

Youtie, J., and Bozeman, B. (2014). Social dynamics of research collaboration: norms, practices, and ethical issues in determining coauthorship rights. Scientometrics 101:962. doi: 10.1007/s11192-014-1 391-7

Conflict of Interest: The authors declare that the research was conducted in the absence of any commercial or financial relationships that could be construed as a potential conflict of interest.

Publisher's Note: All claims expressed in this article are solely those of the authors and do not necessarily represent those of their affiliated organizations, or those of the publisher, the editors and the reviewers. Any product that may be evaluated in this article, or claim that may be made by its manufacturer, is not guaranteed or endorsed by the publisher.

Copyright (c) 2022 Meißner, Weinmann and Vowe. This is an open-access article distributed under the terms of the Creative Commons Attribution License (CC BY). The use, distribution or reproduction in other forums is permitted, provided the original author(s) and the copyright owner(s) are credited and that the original publication in this journal is cited, in accordance with accepted academic practice. No use, distribution or reproduction is permitted which does not comply with these terms. 